\title{
ANALISIS KETERLAKSANAAN MODEL ATTENTION, RELEVANCE, CONFIDENCE, AND SATISFACTION PADA PEMBELAJARAN HIDROKARBON DAN PENGARUHNYA TERHADAP KEPERCAYAAN DIRI SISWA
}

\author{
Abu Bakar ${ }^{1}$, Fatria Dewi $^{2}$, dan Syafira ${ }^{3}$ \\ Jurusan Pendidikan MIPA FKIP Universitas Jambi, Kampus Pinang Masak, Jambi, \\ Indonesia Mendalo Darat Jambi 36361 \\ e-mail ${ }^{1}$ :abu.bakar@unja.ac.id \\ e-mail': $\overline{\text { fatria.dewi@unja.ac.id }}$
}

\begin{abstract}
Abstrak
Penelitian ini bertujuan untuk mengetahui keterlaksanaan model ARCS dan mengetahui pengaruh antara keterlaksanaan model ARCS terhadap kepercayaan diri siswa di SMAN 2 Kota Jambi pada pembelajaran hidrokarbon. Desain penelitian ini adalah pre-experimental desain dengan jenis penelitian one shot case study menggunakan sampel penelitian random sampling. Adapun sampel yang dipilih hanya satu kelas yaitu kelas XI IPA 2. Instrumen penelitian berupa lembar lembar observasi keterlaksanaan model ARCS baik dari guru maupun siswa, serta lembar observasi kepercayaan diri siswa. Data kuantitatif diuji normalitas dan homogenitasnya kemudian dicari hubungan keterlaksanaan model ARCS dan kepercayaan diri siswa dengan korelasi produk momen. Selanjutnya dilakukan uji-t untuk melihat signifikansi pengaruh keterlaksanaan modelARCS dengan kepercayaan diri siswa. Keterlaksanaan model ARCS oleh guru dan siswa termasuk dalam kategori sangat baik dengan persentase $90,77 \%$ dan $91 \%$. Untuk kepercayaan diri siswa dalam kategori baik yaitu dengan persentase $82,25 \%$. Data guru dan siswa berdistribusi normal dan homogen, koefisien korelasi yang diperoleh yaitu sebesar 0,525 , berarti hubungan antara keterlaksanaan model ARCS dengan kepercayaan diri siswa memiliki tingkat hubungan sedang.
\end{abstract}

Kata kunci: Model ARCS, Kepercayaan Diri, Hidrokarbon.

\begin{abstract}
This study aims to determine the implementation of ARCS model and to know the influence between the implementation of ARCS model to students' self confidence in SMAN 2 Jambi City on hydrocarbonlearning. The design of this research is pre-experimental design with type of research one shot case study using random sampling. The sample is selected only one class that is eleventh grade science study. The research instrument in the form of observation sheet of the implementation of ARCS model of both teachers and students, as well as student confidence observation sheet. The quantitative data is tested for normality and homogeneity and then sought the correlation between the ARCS model and the students' confidence with the moment product correlation. Then t-test is done to see the significance of the effect of ARCS model with student's self confidence. Implementation of ARCS model by teachers and students included in very good category with percentage $90,77 \%$ and $91 \%$. For students' self confidence in good category that is with percentage $82,25 \%$. Data of teacher and student is normal and homogeneous distribution, correlation coefficient obtained that is equal to 0,525 , mean relation between implementation of ARCS model with student self confidence have medium relation level.
\end{abstract}

Keywords: ARCS Model, Self Confidence, Hydrocarbon. 


\section{J. Indo. Soc. Integ. Chem., 2017, Volume 9, Nomor 2}

\section{PENDAHULUAN}

Pendidikan adalah usaha sadar yang dengan sengaja dirancang untuk mencapai tujuan-tujuan yang telah ditetapkan salah satunya bertujuan untuk meningkatkan kualitas sumber daya manusia ${ }^{12)}$. Pendidikan juga bertujuan untuk membentuk kemampuan individu mengembangkan dirinya sehingga bermanfaat untuk kepentingan hidupnya sebagai seorang individu, maupun sebagai warganegara dan warga masyarakat ${ }^{3)}$.

Belajar merupakan kegiatan sehari-hari bagi siswa sekolah. Kegiatan ini dilakukan secara sadar dan terencana yang mengarah pada pencapaian tujuan dari kegiatan belajar yang sudah dirumuskan dan diterapkan sebelumnya.Keberhasilan siswa dalam belajar tidak terlepas peran aktif guru yang mampu memberi motivasi dan dapat menciptakan iklim belajar yang harmonis, kondusif, menyenangkan, dan mampu memberi semangat kepada siswa ${ }^{9)}$.

Faktor-faktor yang mempengaruhi hasil belajar siswa terdapat dua faktor yaitu: pertama, faktor internal yaitu faktor yang bersumber dari dalam diri siswa.

Faktor initerdiri dari faktor jasmaniah yaitu: kesehatan dan cacat tubuh, faktor psikologis yaitu: perhatian, minat, bakat, intelegensi dan kesiapan dan faktor kelelahan. Kedua, faktor eksternal yaitu faktor yang bersumber dari luar diri $\operatorname{siswa}^{10)}$

Rasa percaya diri sangat mempengaruhi hasil belajar siswa di sekolah. Kepercayaan diri pada dasarnya merupakan keyakinan dalam diri seseorang untuk dapat menanggapi segala sesuatu dengan baik sesuai dengan kemampuan diri yang dimiliki. Siswa yang memiliki sikap percaya diri dan memiliki penilaian positif tentang dirinya cenderung menampilkan prestasi yang baik secara terus menerus. Sikap percaya diri, yakin akan berhasil, perlu ditanamkan kepada siswa untuk mendorong mereka agar berusaha dengan maksimal guna mencapai keberhasilan yang optimal ${ }^{13)}$.

Berdasarkan hasil observasi pra penelitian yang dilakukan di sekolah dapat dilihat bahwa siswa kelas XI IPA SMAN 2 Kota Jambi kurang percaya diri, gejala yang nampak yaitu: cenderung malu-malu dalam mengungkapkan pendapatnya. Ketika siswa selesai mengerjakan tugas tidak ada satupun diantara mereka yang memiliki inisiatif sendiriuntuk mempresentasikan hasil kerjanya. Saatguru meminta salah satu siswa untuk maju sekedar menceritakan atau membacakan hasilkerjanya maka akan terjadi saling tunjuk antar siswa. Siswa terlihat enggan untuk maju dikarenakan sikap malu yang ada pada diri siswa. Ketika siswa membaca 


\section{J. Indo. Soc. Integ. Chem., 2017, Volume 9, Nomor 2}

di depan kelas suara yang mereka keluarkan juga masih pelan. Mereka cenderung tidak menggunakan kualitas suara yang seharusnya. Perilaku yang dimunculkan oleh para siswa adalah pencerminan dari mereka yang kurang memiliki rasa percaya diri dalam belajar sehingga akan berdampak terhadap nilai yang diperolehnya dalam belajar.

Materi hidrokarbon merupakan materi yang membutuhkan pemahaman konsep lebih, apabila siswa kurang memahami konsep mereka akan kesulitan dalam mempelajari materi. Materi pokok hidrokarbon mencakup rumus senyawasenyawa serta sifat fisis dan reaksi-reaksi yang terjadi pada senyawa hidrokarbon. Dalam materi ini juga banyak hal yang berkaitan dengan kehidupan sehari-hari. Namun, siswa tidak mengetahui keterkaitan antara materi dengan kehidupan sehari-hari, mereka hanya berpedoman pada bahan ajar yang diberikan oleh guru. Hal ini membatasi pengetahuan dan menjadikan siswa cepat bosan selama pelajaran.

Berkaitan dengan hal di atas,salah satu model pembelajaran yang dapat diterapkan dalam kelas dalam rangka meningkatkan kepercayaan diri siswa sehingga dapat membantu siswa mengatasi kesulitan belajar, menghilangkan persepsi buruk siswa terhadap pelajaran kimia khususnya pada materi hidrokarbon adalah model
Attention, Relevance, Confidence, And Satisfaction (ARCS). Model pembelajaran ini mengaitkan materi dengan penggunaannya dalam kehidupan seharihari, sehingga lebih menarik perhatian siswa. Model ARCS mengandung aspek perhatian (attention), kesesuaian (relevance), percaya diri (confidence), dan kepuasan (satisfaction) dalam sintaks pembelajarannya. Dalam komponen model pembelajaran ini terdapat komponen confidence (percaya diri) yang dapat mendorong dan meningkatkan kepercayaan diri siswa.

Pembelajaran kimia seharusnya dilakukan dengan model pembelajaran yang menarik dan sesuai, menuntut siswanya aktif serta bermakna bagi siswa. Oleh karena itu perlu adanya strategi khusus ataupun perubahan-perubahan dalam kegiatan pembelajaran kimia yang dilakukan oleh guru terutama dalam mengembangkan percaya diri pada siswa.

Beberapa penelitian terdahulu telah membuktikan keefektifan dari model pembelajaran ARCS yaitu dapat meningkatkan kepercayaan diri siswa ${ }^{11)}$. Namun dari beberapa penelitian yang telah menggunakan model ARCS belum meneliti bagaimana keterlaksanaan model ARCS yang ditinjau dari guru maupun siswa, sementara keterlaksanaan model pembelajaran sangat erat kaitannya dengan 


\section{J. Indo. Soc. Integ. Chem., 2017, Volume 9, Nomor 2}

kepercayaan diri siswa. Untuk itu perlu diadakan analisis keterlaksanaan model ARCS ditinjau dari guru dan siswa, sehingga akan terlihat apakah pelaksanaan model ARCS berpengaruh terhadap kepercayaan diri siswa.

Berdasarkan latar belakang tersebut, maka peneliti memilih judul penelitian "Analisis Keterlaksanaan Model Pembelajaran Attention, Relevance, Confidence, And Satisfaction pada Pembelajaran Hidrokarbon dan Pengaruhnya Terhadap Kepercayaan Diri Siswa Kelas XI IPA SMAN 2 Kota Jambi”.

\section{METODE PENELITIAN}

Desain penelitian ini adalah preexperimental desain dengan jenis penelitian one shot case study menggunakan sampel penelitian random sampling.Subjek dalam penelitian ini adalah siswa kelas XI IPA SMAN 2 Kota Jambi tahun ajaran 2017/2018 yang terdiri dari 1kelas.

Variabel bebas dalam penelitian ini adalahketerlaksanaan model pembelajaran model $A R C S$ dan ariabel terikatnya adalah kepercayaan diri siswa.

Instrumen penelitian berupa lembar lembar observasi keterlaksanaan model ARCS baik dari guru maupun siswa, serta lembar observasi kepercayaan diri siswa. Data kuantitatif diuji normalitas dan homogenitasnya kemudian dicari hubungan keterlaksanaan model ARCS dan kepercayaan diri siswa dengan korelasi produk momen.

$$
\begin{aligned}
& r_{x y} \\
& =\frac{N \Sigma x-\left(\sum x\right)\left(\sum y\right)}{\sqrt{\left\{N \Sigma x^{2}-\left(\sum x\right)^{2}\left(N \Sigma y^{2}-(\Sigma y)^{2}\right\}\right.}}
\end{aligned}
$$

(Sugiyono, 2013)

Kisi-kisi instrumen keterlaksanaan model diambil dari sintak model ARCS itu sendiri dan dikembangkan berdasarkan kebutuhan. Indikator kepercayaan diri siswa terdiri dari ciri-ciri kepercayaan diri yang diambil dari beberapa teori yang terdiri dari 6 aspek yang diamati.Aspek tersebut dijabarkan menjadi 32 indikator.

Data keterlaksanaan model pembelajaran ARCS dan kepercayaan diri siswa dikumpulkan dengan cara pengamatan langsung tiap pertemuan saat proses pembelajaran berlangsung dengan menggunakan lembar observasi. Pengamatan dilakukan oleh 7 observer. Tiap kelompok siswa diamati oleh 1 orang observer.Dalam penelitian ini terdapat 6 kelompok siswa yang diamati oleh masingmasing observer, sementara 1 orang mengamati keterlaksanaan model pembelajaran ARCSoleh guru. Sedangkan data kerpercayaan dirisiswa diperoleh melalui Lembar observasi yang sesuai dengan instrumen kepercayaan diri siswa terdiri dari 32 pernyataan. 
Sebelum dilakukan pengujian hipotesis terlebih dahulu data keterlaksanaan model pembelajaran ARCSoleh guru dan siswa dilakukan uji kesamaan dua rata-rata dengan syarat data berdistribusi normal dan homogen. Pengujian hipotesis untuk melihat pengaruh keterlaksanaan model ARCS terhadap kepercayaan diri siswa dilakukan dengan menggunakan uji korelasi produk moment dan uji signifikansi yaitu uji-t.Rumus untuk uji t :

$$
t=\frac{r \sqrt{n-2}}{\sqrt{1-r^{2}}}
$$

Keterangan :

$r=$ Koefesien korelasi

$n=$ Banyak sampel

(Sugiyono, 2013)

\section{HASIL DAN PEMBAHASAN}

Analisis data hasil lembar observasi mengindikasikan bahwa guru telah melaksanakan pembelajaran menggunakan model ARCS dengan sangat baik dan mengalami peningkatan disetiap pertemuannya. Data yang diperoleh dirataratakan dengan perolehan persentase sebesar 90,77\% dengan kategori sangat baik. Hal tersebut dapat dilihat pada tabel dan diagram berikut.
Tabel 1 Hasil lembar observasi guru

\begin{tabular}{|c|c|c|}
\hline Pertemuan & Persentase (\%) & Kategori \\
\hline 1 & 85 & Sangat Baik \\
\hline 2 & 92,50 & Sangat Baik \\
\hline 3 & 95 & Sangat Baik \\
\hline Rata-rata & 90,77 & Sangat Baik \\
\hline
\end{tabular}

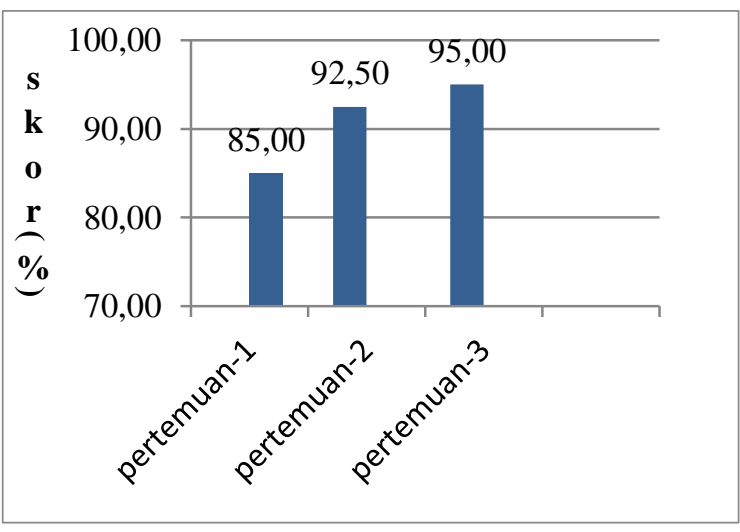

Gambar 1 Diagram persentase keterlaksanaan model ARCS oleh guru

Sama halnya dengan peningkatan keterlaksanaan model oleh guru, persentase keterlaksanaan model oleh siwa juga mengalami peningkatan disetiap pertemuannya. Data yang diperoleh dirataratakan dengan perolehan persentase sebesar 91\% dengan kategori sangat baik. Hal tersebut dapat dilihat pada tabel dan diagram berikut.

Tabel 2 Hasil lembar observasi siswa

\begin{tabular}{|c|c|l|}
\hline Pertemuan & Persentase (\%) & Kategori \\
\hline 1 & 88 & Sangat Baik \\
\hline 2 & 91 & Sangat Baik \\
\hline 3 & 92 & Sangat Baik \\
\hline Rata-rata & 91 & Sangat Baik \\
\hline
\end{tabular}




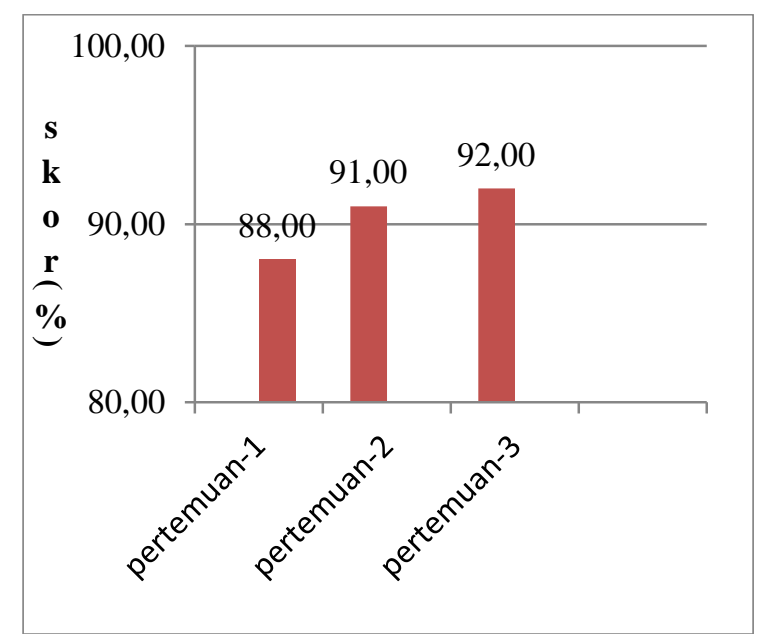

Gambar 2 Diagram persentase keterlaksanaan model ARCS oleh siswa

Data keterlaksanaan model ARCS oleh guru dan siswa diuji normalitas dan homogenitas. Setelah didapatkan data berdistribusi normal dan homogen maka dilanjutkan dengan uji kesamaan dua ratarata. Hasil perhitungan diperoleh nilai $t_{\text {hitung }}$ 0,895 dan $t_{\text {tabel }} 2,776$ sehingga dapat diketahui bahwa harga $-\mathrm{t}_{\text {tabel }}<\mathrm{t}_{\text {hitung }}<\mathrm{t}_{\text {tabel }}$ yaitu $-2,776<0,895<2,776$. Kesimpulannya bahwa data keterlaksanaan model ARCS oleh siswa dapat mewakili data keterlaksanaan model ARCS oleh guru.

Data kepercayaan diri siswa menunjukkan bahwa persentase kepercayaan diri siswa mengalami peningkatan disetiap pertemuannya. Data yang diperoleh dirata-ratakan dengan perolehan persentase sebesar 82,25\% dengan kategori baik. Hal tersebut dapat dilihat pada tabel dan diagram berikut.
Tabel 3 Hasil lembar observasi kepercayaan diri siswa

\begin{tabular}{|c|c|c|}
\hline Pertemuan & Persentase (\%) & Kategori \\
\hline 1 & 73,75 & Baik \\
\hline 2 & 86 & Sangat Baik \\
\hline 3 & 87 & Sangat Baik \\
\hline Rata-rata & 82,25 & Baik \\
\hline
\end{tabular}

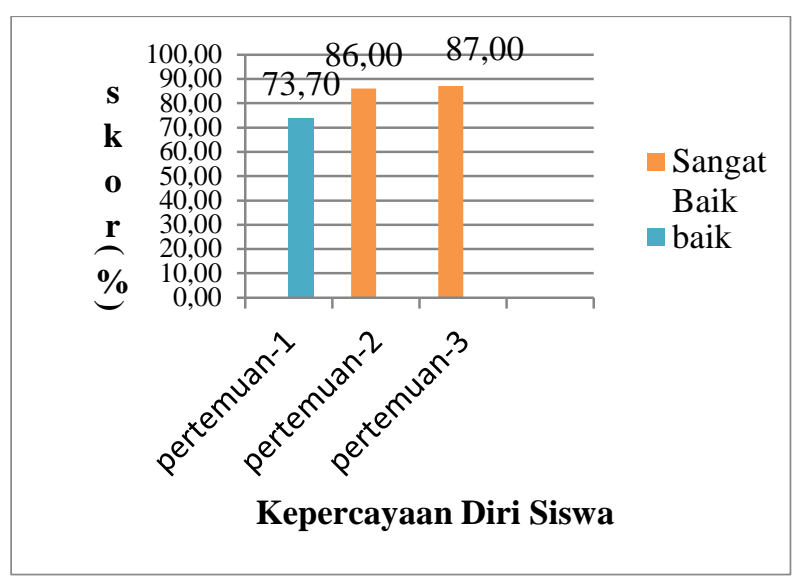

Gambar 3 Diagram Persentase Hasil Observasi Kepercayaan Diri Siswa

Peningkatan kepercayaan diri siswa dalam penelitian ini bukan semata-mata karena ketidaksengajaan namun dikarenakan keterlaksanaan model pembelajaran ARCS berjalan dengan baik dan guru semakin menguasai sintaks dengan maksimal dan juga menguasai kelas dengan baik dan terjadinya pembelajaran aktif yaitu dengan berdiskusi antar kelompok, bertukar pikiran, menggugah ide-ide siswa dan bimbingan belajar oleh guru.

Data yang diperoleh kemudian dianalisis untuk melihat pengaruh keterlaksanaan model pembelajaran ARCS terhadap kepercayaan diri siswa dengan 
menggunakan rumus korelasi produk moment. Hasil analisis data menunjukkan tingkat hubungan sedang dengan $r_{x y}=$ 0,525 . Untuk melihat signifikansi antara keterlaksanaan model ARCS dengan kepercayaan diri siswa dilakukan dengan uji lanjutan yaitu uji-t dan didapat $\mathrm{t}_{\text {hitung }}=$ 2,68 dengan $t_{\text {tabel }} 1,6838$ maka $t_{\text {hitung }}$ lebih besar dari $t_{\text {tabel }}(2,68>1,6838)$. Hasil pengujian hipotesis diperoleh terima $\mathrm{Ha}$ dan tolak Ho yang berarti terdapat pengaruh keterlaksanaan model terhadap kepercayaan diri siswa.

\section{KESIMPULAN}

Adapun kesimpulan yang didapat dalam penelitian ini adalah keterlaksanaan model Attention, Relevance, Confidence and Satisfaction pada pembelajaran hidrokarbondan pengaruhnya terhadap kepercayaan dirisiswa di kelas XI IPA SMAN 2 Kota Jambi berjalan dengan baik dan mengalami peningkatan tiap pertemuan ditinjau dari guru maupun siswa. Selain itu terdapat pengaruh positif model pembelajaran Attention, Relevance, Confidence and Satisfaction pada pembelajaran hidrokarbon terhadap kepercayaan dirisiswa di kelas XI IPA SMAN 2 Kota Jambi

\section{DAFTAR PUSTAKA}

1. Awoniyi., 1997, Strength and Weakness of ARCS Model. Diakses 20 April 2017,dari http://ouray.cudenver.edu.
2. Baron, R. A. \& Byrne, D., 2004, Psikologi Sosial (edisi 10). Jakarta :Penerbit Erlangga

3. Darmadi, H., 2012, Belajar dan Pembelajaran. Bandung: Rosdakarya.

4. Ghufron., 2011, Teori-Teori Psikologi. Yogyakarta: Ar-Ruzz Media.

5. Keller, J., 1994, Development and use of the arcs model of instructional design. Journal of Instructional Development. 10(3): 2-10.

6. Kiranawati., 2007, Metode Investigasi Kelompok. Jakarta: PT. Raja Grafindo Persada.

7. Lauster, P, diterjemahkan oleh D.H. Gulo., 2002, Tes kepribadian. Jakarta: Bumi Aksara.

8. Mertasari, T., 2003, Psikologi Perkembangan Anak dan Remaja Terjemahan. Jakarta: Balai Pustaka.

9. Pratiwi., 2014, Belajar dan Pembelajaran. Jakarta: Gramedia Pustaka Utama.

10. Rachman, S., 2010, Hubungan Tingkat Percaya Diri dengan Hasil Belajar. Jakarta: Uin Syarif Hidayatullah.

11. Reskiwati S., 2014, Efektivitas Penggunaan Model Pembelajaran Kooperatif Tipe Think Pair Share (Tps) Untuk Meningkatkan Kepercayaan Diri Dan Komunikasi Matematis Siswa Sman 9 Makassar .Jurnal Nalar Pendidikan Volume 2, Nomor 2, Juli-Desember 2014. ISSN: 2339-0794 Halaman [230].

12. Sahertian., 2010, Konsep Dasar dan Teknik Super Visi Pendidikan Dalam Rangka Pengembangan Sumber Daya Manusia. Jakarta: PT Rineka Cipta.

13. Slameto., 2010, Belajar dan FaktorFaktor yang Mempengaruhinya. Jakarta: Rineka.

14. Sugiyono., 2013, Metode Penelitian Kuantitatif, Kualitatif dan $R \& D$. Bandung: Alfabet 